J. Clin. Chem. Clin. Biochem.

Vol. 15, 1977, pp. 89-91

\title{
Vergleich von Aminosäuren in menschlichem Serum und Plasma
}

\author{
Von N. R. Katz und M. Keck
}

Abteilung Innere Medizin IV (Komm. Direktor: Prof. Dr. R. Kluthe) der Universität Freiburg

(Eingegangen am 10. August/14. Oktober 1976)

Zusammenfassung: Unter standardisierten Bedingungen werden die Aminosäuren in Serum und Plasma bestimmt und miteinander verglichen. Nach unmittelbar im Anschluß an die Blutabnahme erfolgter Probenvorbereitung sind die untersuchten Aminosäurekonzentrationen in Serum und Plasma gleich. Findet die Enteiweißung allerdings erst nach 10 oder 24-stündigem Stehen des Serums bei $4{ }^{\circ} \mathrm{C}$ oder $22^{\circ} \mathrm{C}$ statt, sind verschiedene Aminosäurekonzentrationen gegenüber den Ausgangswerten signifikant verändert.

\section{Comparison of amino acids in human serum and plasma}

Summary: Using standardized analytical methods amino acids in human serum and plasma were compared. Identical concentrations of the studied amino acids are found in serum and plasma,.which are prepared immediately after blood sampling. If protein precipitation is performed after storage of the serum sample at $4{ }^{\circ} \mathrm{C}$ or $22^{\circ} \mathrm{C}$ for 10 or 24 hours, concentrations of some amino acids are significantly changed.

\section{Einleitung}

In Untersuchungen über das Verhalten von Aminosäuren im Blut werden entsprechende Konzentrationsangaben bevorzugt für Plasma und nur vereinzelt für Serum angegeben. Da die Mehrzahl aller klinisch-chemischen Laboruntersuchungen des Blutes jedoch im Serum vorgenommen werden, erscheint es wïnschenswert, auch die Aminosäurebestimmung im Serum vorzunehmen. Wie sich im Rahmen einer Untersuchung an Heimdialysepatienten zeigte $(1,2)$ ist dies besonders dort von Vorteil, wo Blutabnahme und das Abtrennen von zellulären Blutbestandteilen außerhalb der Klinik erfolgen. Hinsichtlich der Vergleichbarkeit von Serum- und Plasmaaminosäuren liegen in der Literatur widersprüchliche Angaben vor (3-6). Dies scheint im wesentlichen auf unterschiedliche Versuchs- und Analysebedingungen zurückzuführen sein. In der vorliegenden Arbeit wurden daher Serum- und Plasmaaminosäuren nach exakt standardisierter Aufarbeitung des jeweiligèn Untersuchungsmaterials miteinander verglichen. Darüber hinaus wurden Veränderungen des Aminosäurespektrums in Abhängigkeit vom Intervall zwischen Serumgewinnung und Enteiweißung untersucht.

\section{Material und Methoden}

Zwölf gesunden Versuchspersọnen im Alter żwisọhen 21 ụnd 35 Jahren ( 7 Männeri, 5 Frauen) wurde morgens nüchtern aus der leicht gestauten Vena cubitalis in zwei Zentrifugenröhrchen ohne bzw. mit Lithiumheparinat-Zusatz $(0,75 \mathrm{~g} / 1$ Blut) Blut abge- nommen. Beide Proben wurden verschlossen, vorsichtig durchmischt und nach 15 minütigem Stehen bei $4^{\circ} \mathrm{C}$ in der Kühlzentrifuge bei $4^{\circ} \mathrm{C} 10$ Minuten mit $6000 \mathrm{~g}$ zentrifugiert. Der klare Serum- bzw. Plasmaüberstand wurde abpipettiert und durch Zugabe von $0,4 \mathrm{ml} 150 \mathrm{~g} / 1$ Sulfosalicylsäure zu 1,6 ml Serum oder Plasma unter kräftigem Umschütteln enteiweißt. Das präzipitierte Protein wurde nach einstündigem Stehen im Eis in der Kühlzentrifuge abgetrennt. Vom klaren enteiweißten Überstand wurde $1 \mathrm{ml}$ entnommen und mit $0,6 \mathrm{ml} \mathrm{0,1} \mathrm{mol} / 1$ Lithiumcitratpuffer pH 2,2 (7) versetzt. Die so vorbereiteten Proben blieben bis zur Aminosäurenanalyse bei $-30^{\circ} \mathrm{C}$ eingefroren.

Von sechs Probanden wurde darüber hinaus je ein Aliquot des Serums 4, 10 und 24 Stunden bei $4^{\circ} \mathrm{C}$ sowie in einer weiteren Serie entsprechend lange bei $22^{\circ} \mathrm{C}$ (Raumtemperatur) vor der Enteiweißung aufbewahrt. Die weitere Aufarbeitung erfolgte wie beschrieben.

Die chromatographische Trennung der Aminosäuren wurde in einem Anàlysator LC 4010 (Biotronik, D-8000 München) an Ionenaustauscherharz DC 1 A (Durrum, Palo Alto/Californien) auf einer $50 \times 0,9 \mathrm{~cm}$ Säule vorgenommen. Die Elution erfolgte mit Lithiumcitrat Puffern modifiziert nach Kedenburg (8). Das Ninhydrin-Reagenz war nach Spackman et al. (9) hergestellt. Für jede Analyse wurden 0,5 ml vorbereitete Probe entsprechend $0,25 \mathrm{ml}$ nativem Serum bzw. Plasma eingesetzt. Die Kalibrierung erfolgte mit Aminosäure-Standard-Gemisch (Hamilton, Californien); alle übrigen Reagenzien wurden von $\mathrm{E}$. Merck, D-6100 Darmstadt bezogen.

Zur mathematischen Auswertung der photometrischen Bestimmung der getrennten Aminosäuren diente ein Integrator Autolab System I (Spectra Physics, D-6100 Darmstadt).

\section{Ergebnis und Diskussion}

Beim Vergleichen der Aminosäurekonzentrationen in Serum und Plasma, die jeweils innerhalb von 30 Minuten 
nach Blutentnahme enteiweißt worden waren, zeigten sich keine über die Fehlerbreite der Bestimmungsmethode hinausgehenden Unterschiede entsprechender Aminosäurenwerte (Tab. 1). Da sich Serum im wesentlichen durch das Fehlen von Fibrinogen $(2-3 \mathrm{~g} / \mathrm{l})$ von Plasma unterscheidet, ist die Konzentration gelöster Substanzen im Serum dadurch geringfügig höher als im Plasma. Unter Berücksichtigung der Genauigkeit der Bestimmungsmethode ist dieser Unterschied für Aminosäuren allerdings vernachlässigbar klein. Daher können unter den beschriebenen Versuchs- und Analysenbedingungen gewonnene Angaben der Aminosäurekonzentration in Serum und Plasma als gleichwertig angesehen werden. Gegenüber Plasma geringfügig oder deutlich erhöhte Aminosäurekonzentrationen im Serum, wie sie vor allem von Armstrong \& Stave (6)

Tab. 1. Vergleich von Aminosäuren in Serum und Plasma. Plasmawerte in Prozent der Serumwerte. Aminosäurekonzentration im Serum $=100 \%(n=12)$.

\begin{tabular}{lr}
\hline & $\begin{array}{c}\text { Aminosäuren im Plasma } \\
\text { \% der Serumwerte } \pm \mathrm{s}\end{array}$ \\
\hline Glycin & $99,4 \pm 1,86$ \\
Alanin & $99,3 \pm 3,08$ \\
Glutamin & $99,2 \pm 10,81$ \\
Glutaminsäure & $97,8 \pm 8,20$ \\
Asparagin & $95,1 \pm 10,20$ \\
Serin & $98,8 \pm 2,77$ \\
1/2 Cystin & $99,9 \pm 7,45$ \\
Citrullin & $102,6 \pm 18,20$ \\
Ornithin & $99,1 \pm 7,91$ \\
Histidin & $98,9 \pm 5,03$ \\
Arginin & $102,3 \pm 6,90$ \\
Tyrosin & $100,2 \pm 6,02$ \\
Phenylalanin & $99,6 \pm 5,21$ \\
Threonin & $98,6 \pm 2,32$ \\
Valin & $99,6 \pm 3,28$ \\
Leucin & $100,4 \pm 3,82$ \\
Isoleucin & $101,9 \pm 4,36$ \\
Methionin & $97,0 \pm 4,77$ \\
Lysin & $98,4 \pm 4,17$ \\
\hline
\end{tabular}

beschrieben wurden, sind vermutlich auf die unterschiedliche Aufarbeitung von Plasma einerseits und Serum, das erst nach mehrstündigem Stehen enteiweißt wurde, andererseits zurückzuführen. Bei wiederholter Bestimmung desselben Serums oder Plasmas lagen die Variationskoeffizienten für die meisten Aminosäuren zwischen $1,2 \%$ und $3 \%(n=30)$. Ausschließlich Aminosäuren, die mit Ninhydrin nur eine schwache Farbreaktion aufweisen (Asparagin, Prolin) oder im Serum in geringer Konzentration vörliegen (Asparaginsäure, 1- und 3Methyl-Histidin) zeigten bei der Bestimmung eine höhere Variationsbreite. Unter Verwendung von synthetischen Aminosäure-Standard-Gemischen, in denen alle interessierenden Aminosäuren in ausgewogenem Verhältnis vorliegen (50-125 $\mu \mathrm{mol} / \mathrm{l})$, wurden auch für Asparaginsäure sowie die Methyl-Histidine in Übereinstimmung mit Held et al. (10) Variationskoeffizienten um 2\% ermittelt.

Bei wiederholter Bestimmung von Glutamin war in Serum und Plasma gleichermaßen eine vom Alter der enteiweißten Probe abhängige Konzentrationsabnahme zu beobachten, die u. a. auf Deamidierung zurückzuführen ist und sich selbst durch Lagèrung der auf $\mathrm{pH}$ 2,2 eingestellten Probe bei $-30^{\circ} \mathrm{C}$ nicht vollständig verhindern läßt (6). Entsprechend war ein geringer Anstieg der Glutaminsäure und des Ammoniaks festzustellen.

Seren, die bis zur Enteiweißung vier Stunden bei $4{ }^{\circ} \mathrm{C}$
gelagert wurden, wiesen mit Ausnahme der Asparagin-
säure gegenüber Plasma und sofort enteiweißtem Serum
keine über die Fehlerbreite der Bestimmungsmethode
hinausgehende Veränderungen der Aminosäurespiegel
auf. Erfolgte die Enteiweißung allerdings erst nach 10
oder 24 -stündiger Lagerung der Seren bei $4{ }^{\circ} \mathrm{C}$ bzw.
$22{ }^{\circ} \mathrm{C}$, so waren signifikante Konzentrations-
änderungen verschiedener Aminosäuren gegenüber sofort
enteiweißtem Serum zu beobachten (Tab. 2). Während

Tab. 2. Abhängigkeit der Serumaminosäure-Konzentrationen von der Dauer zwischen Serumgewinnuñg und enteiweißung $(N=6)$. Signifikante Veränderungen gegenüber dem Ausgangswert $(p<0.02)$ bestanden bei den kursiv gesetżten Werten.

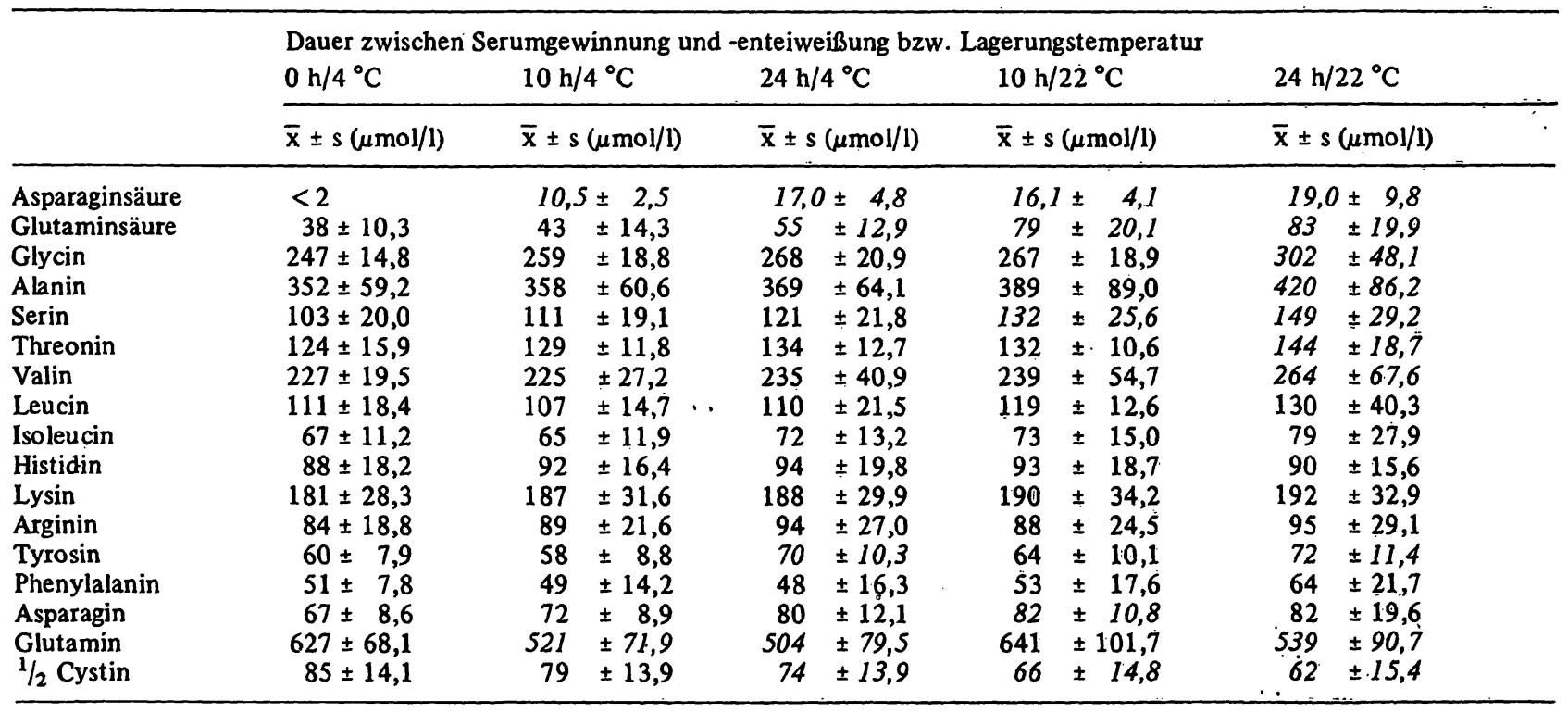


die Mehrzahl der Aminosäuren im Serum mit zunehmendem Intervall zwischen Blutabnahme und Enteiweißung mehr oder minder deutlich anstieg, nahm der Gehalt von Cystin und Cystein im Serum bei $4^{\circ} \mathrm{C}$ und deutlicher noch bei $22^{\circ} \mathrm{C}$ ab. Glutamin wies bei kühler Lagerung des Serums eine Konzentrationsabnahme auf, während bei $22^{\circ} \mathrm{C}$ innerhalb der ersten 10 Stunden keine signifikante Änderung auftrat und erst danach eine Emiedrigung des Glutaminspiegels zu beobachten war. Offensichtlich war hier ähnlich wie bei Asparagin eine Deamidierung durch proteolytisch bedingte Erhöhung der Aminosäure überlagert. Am stärksten imponierte die Konzentrationszunahme der Asparaginsäure, da hier mäßige absolute Veränderung mit einer Vervielfachung des Ausgangswertes verbunden war. Ein entsprechendes Verhalten war in geringerem Umfang auch bei Glutaminsäure $\mathrm{zu}$ beobachten.

Glycin, Alanin, Serin und Threonin wiesen in der Kälte allenfalls eine leichte, bei Lagerung um $22^{\circ} \mathrm{C}$ im Durchschnitt eine mäßige Konzentrationszunahme auf. Bei den essentiellen Aminosäuren Valin, Leucin, Isoleucin und Phenylalanin waren im Mittel erhöhte Serumspiegel nur nach Lagerung bei $22^{\circ} \mathrm{C} \mathrm{zu}$ beobachten. wegen des niedrigen physiologischen Serumspiegels eine

weise unterschiedlich stark ausgeprägt waren. Dieses unterschiedliche, individuelle Verhalten ließ sich weder mit Alter noch Geschlecht der Probanden korrelieren. Es war daher unvorhersehbar, ob ein Serum nach längerem Stehen vor der Enteiweißung geringe oder erhebliche Veränderungen der Aminosäurekonzentration aufwies.

Die Gewinnung und Aufarbeitung der Seren wurde durch Verwenduing von Einmalgefäßen und -pipetten unter konstant keimarmen Bedingungen vorgenommen. Es ist daher unwahrscheinlich, daß unterschiedliche mikrobielle Verunreinigung zumal bei kühl gelagerten Serumproben für die unterschiedlich ausgeprägten individuellen Veränderungen der Aminosäuren verantwortlich sind. Vermutlich handelt es sich hierbei eher um Desorption einzelner Aminosäuren von Proteinen sowie um spezifische und unspezifische Proteolyse.

Ungeachtet der Ursachen für die beschriebenen Veränderungen sollte Serum für die Aminosäurenanalyse möglichst umgehend, jedoch nicht wesentlich später als vier Stunden nach Blutabnahme und unmittelbar anschlieBender Abtrennung zellulärer Blutbestandteile enteiweißt werden. Bis zur Proteinfällung sollte das Serum kühl gelagert werden. Unter diesen Bedingungen sind Serum und Plasmaaminosäuren miteinander vergleichbar und entsprechen offensichtlich physiologischen

Aufbewahren des Serums vor der Enteiweißung nicht signi- Werten.

fikant verändert worden zu sein.

Trotz dieser im Mittelwert teilweise unerheblichen $\mathrm{Zu}$ oder Abnahmen einzelner Aminosäuren sollten Seren, die nach mehr als vierstündiger Lagerung enteiweißt wurden, möglichst nicht mehr zur Analyse der Aminosäuren verwendet werden, da lagerungsbedingte Veränderungen von Versuchsperson zu Versuchsperson teil-

\section{Danksagung}

Herrn Dr. G. Schaeffer danken wir für die freundliche Anleitung und Durchsicht der statistischen Auswertung.

Die Arbeit wurde mit Unterstützung durch die Deutsche Forschungsgemeinschaft durchgeführt.

\section{Literatur}

1. Schaeffer, G., Heinze, V., Jontofsohn, R., Katz, N., Rippich, Th., Schäfer, B., Südhoff, A., Zimmermann, W. \& Kluthe, R. (1975), Clin. Nephrol. 3, 228-233.

2. Zimmermann, W., Schaeffer, G., Schäfer, B., Katz, N., Südhoff, A. \& Kluthe, R. (1976), Nieren- und Hochdruckkrankheiten 5, 72-76.

3. MacFayden, D. A. (1942), J. Biol. Chem. 145, 387-403.

4. Christensen, H. C. \& Lynch, E. L. (1946), J. Biol. Chem. $163,741-751$.

5. Oepen, H. \& Oepen, J. (1963), Klin. Wochenschr. 4l, 1048-1050.

6. Armstrong, M. D. \& Stave, U. (1973), Metabolism 22, $549-560$

7. Benson, J. V., Jr., Gordon, M. J. \& Patterson, J. A. (1967), Anal. Biochem. 18, 228-240.

8. Kedenburg, C.-P. (1971), Anal. Biochem. 40, 35-42.

9. Spackman, D. H., Stein, W. H. \& Moore, S. (1958), Anal. Chem. 30, 1190-1206.

10. Held, E., Winkelmann, W., Finke, K., v. Dehn, H., Seyffart, G. \& Gurland, H. J. (1974), Klin. Wochenschr. 52 . 974-978.
M. Keck

Abteilung Innere Medizin IV der Universität Freiburg

Wonnhalde $1-5$

D-7800 Frciburg 
